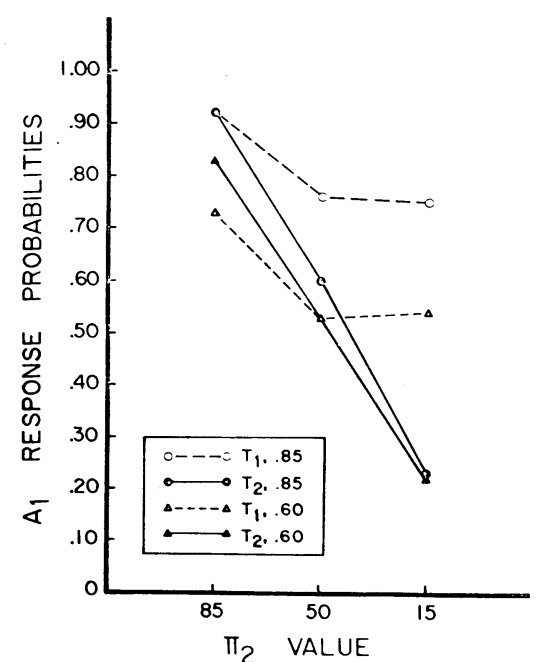

Fig. 2. Probabilities of predicting $E_{1}$ on $T_{1}$ and $T_{2}$ trials plotted as a function of $\pi_{1}$ and $\pi_{2}$ for the last trial block.

A final comparison of interest may be made between those groups for which $\pi_{1}$ is .85 and similar groups in the Popper \& Atkinson (1958) experiment in which the primary concern was the shape of the function relating $P\left(A_{1} \mid T_{1}\right)$ to $\pi_{2}$. The relevant data are shown in Fig. 2.

The major difference in the functions obtained in the two studies is the data obtained in the $.85 / .15$ condition. Popper and Atkinson found $P\left(A_{1} \mid T_{1}\right)$ and $P\left(A_{1} \mid T_{2}\right)$ to slightly overshoot $\pi_{1}$ and to undershoot $\pi_{2}$. The values obtained with the alternating sequence in the present experiment are at .75 and .25 after a comparable number of trials. It is possible that the same stimulus-generalization mechanism usually postulated for these data can account for the discrepancy; some

Table 1

Probability of an $\mathbf{A}_{1}$ Response Conditional on the Outcome of the Preceding Trial*

\begin{tabular}{|c|c|c|c|c|}
\hline \multirow[b]{2}{*}{ Group } & \multicolumn{4}{|c|}{ Outcome of Preceding Trial } \\
\hline & $\mathrm{A}_{1} \mathrm{E}_{1}$ & $\mathrm{~A}_{2} \mathrm{E}_{1}$ & $A_{1} E_{2}$ & $\mathrm{~A}_{2} \mathrm{E}_{2}$ \\
\hline $.85 / .85$ & $\begin{array}{l}.951 \\
.946\end{array}$ & $\begin{array}{l}.691 \\
.692\end{array}$ & $\begin{array}{l}.864 \\
.917\end{array}$ & $\begin{array}{l}.571 \\
.500\end{array}$ \\
\hline $.85 / .50$ & $\begin{array}{l}.796 \\
.613\end{array}$ & $\begin{array}{l}.714 \\
.534\end{array}$ & $\begin{array}{l}.804 \\
.638\end{array}$ & $\begin{array}{l}.702 \\
.571\end{array}$ \\
\hline $.85 / .15$ & $\begin{array}{l}.300 \\
.074\end{array}$ & $\begin{array}{l}.694 \\
.658\end{array}$ & $\begin{array}{l}.311 \\
.195\end{array}$ & $\begin{array}{l}.934 \\
.727\end{array}$ \\
\hline $.60 / .50$ & $\begin{array}{l}.770 \\
.884\end{array}$ & $\begin{array}{l}.510 \\
.624\end{array}$ & $\begin{array}{l}.763 \\
.877\end{array}$ & $\begin{array}{l}.546 \\
.783\end{array}$ \\
\hline $.60 / .50$ & $\begin{array}{l}.437 \\
.440\end{array}$ & $\begin{array}{l}.506 \\
.559\end{array}$ & $\begin{array}{l}.586 \\
.491\end{array}$ & $\begin{array}{l}.620 \\
.683\end{array}$ \\
\hline $.60 / .15$ & $\begin{array}{l}.359 \\
.139\end{array}$ & $\begin{array}{l}.413 \\
.273\end{array}$ & $\begin{array}{l}.400 \\
.215\end{array}$ & $\begin{array}{l}.612 \\
.311\end{array}$ \\
\hline
\end{tabular}

*The first line for each group presents response probabilities on $T_{1}$ trials following the outcomes of $T_{2}$ trials. The second line for each group presents response probabilities on $T_{2}$ trials following the outcomes of $T_{1}$ trials. stimulus component common to both trial types is available for conditioning (Burke \& Estes, 1957; Atkinson, 1958) and is a stronger factor with the alternating than with the random sequence. However, if it were, the $85 / .50$ data sets for the two studies should differ more.

The explanation for the $.85 / .15$ and $.60 / .15$ groups would seem to lie in the fact that there is necessarily a strong event alternation pattern inherent in the overall event sequence. The $S$ adopts a response-alternation strategy, generally making $A_{1}$ responses on Type 1 trials and $\mathrm{A}_{2}$ responses on Type 2 trials. Occasionally, he forgets the previous event or response and slips out of phase for some number of trials. This explanation is consistent with the $P\left(A_{1} \mid T_{1}\right)$ and $\mathrm{P}\left(\mathrm{A}_{1} \mid \mathrm{T}_{2}\right)$ data. More compelling is the manner in which it accounts for the effects of preceding response-event combinations. Ss alternate responses more after having been correct than after having been wrong, a result completely inconsistent with most mathematical models for binary prediction, but perfectly reasonable if it is assumed that the alternation strategy rather than any single prediction is reinforced on each trial. Furthermore, Ss alternate more after having made an $A_{1}$ response on $T_{1}$ or an $A_{2}$ response on $T_{2}$, and they also alternate most in the $.85 / .15$ condition, next in the $.60 / .50$ condition (particularly on Type 2 trials), and next in the $.60 / .50$ condition. These results also follow if it is assumed that the probability of response alternation is a direct function of the probability that such a strategy will be correct.

\section{REFERENCES}

ATKINSON, R. C. A Markov model for discrimination learning. Psychometrika, 1958 $23,309-322$

BRODY, A. L. Independence in the learning of two consecutive responses per trial. Journal of Experimental Psychology, 1958, 56, 16-20.

BURKE, C. J., \& ESTES, W. K. A componen model for stimulus variables in discrimination learning. Psychometrika, 1957, 22, 133-145.

MYERS, J. L., \& CRUSE, D. Two-choice discrimination learning as a function of stimulus and event probabilities. Journal of Experimental Psychology, 1968, 77, 453-459.

POPPER, J., \& ATKINSON, R. C. Discrimination learning in a verbal conditioning situation. Journal of Experimental Psychology, 1958, $56,21-25$.

SHAFFER, J. P. Effect of different stimulus frequencies on discrimination learning with probabilistic reinforcement. Journal of Experimental Psychology, 1963, 65, 265-269.

\title{
Stimulus meaningfulness and similarity, recall direction and rate of recall test*
}

\author{
DOUGLAS L. NELSON, JOSEPH WHEELER, and JANE ENGEL \\ University of South Florida, Tampa, Fla. 33620
}

In a previous study, decreases in stimulus meaningfulness and similarity produced increases in the differences between forward and backward recall following paired-associate (PA) acquisition. This experiment indicated that these relationships were not a result of the long recall test interval used. Although the overall level of recall was reduced under a faster test rate, the meaningfulness-similarity recall direction relationships were independent of test rate.

Nelson, Rowe, Engel, Wheeler, \& Garland (1970) found that the relative differences between forward and backward recall increased as stimulus meaningfulness and similarity were decreased. These results were interpreted as being consistent with the assumption that decreasing

*This research was supported by Grant MH 16360 to the first author. meaningfulness and similarity increased the likelihood of partial stimulus coding processes, reducing nominal stimulus availability at recall. However, a relatively slow 8-sec recall test rate was used, with the retrieval cue remaining on the screen for ".ee entire interval. As Ekstrand (1966) has suggested, this long interval might have allowed Ss to "run through" all the stimuli 
Table 1

Means of Correct Recalls Under 2-Sec (8-Sec) Test Rates

\begin{tabular}{llcrc}
\hline $\begin{array}{l}\text { Recall Direction } \\
\text { for Each Type } \\
\text { of Material }\end{array}$ & $\begin{array}{c}\text { High } \\
\text { High } \\
\text { Similarity }\end{array}$ & $\begin{array}{c}\text { Meaningfulness } \\
\text { Low } \\
\text { Similarity }\end{array}$ & $\begin{array}{c}\text { Low } \\
\text { High } \\
\text { Similarity }\end{array}$ & $\begin{array}{c}\text { Meaningfulness } \\
\text { Low } \\
\text { Similarity }\end{array}$ \\
\hline $\begin{array}{l}\text { Trigrams } \\
\text { Forward }\end{array}$ & $5.2(6.3)$ & $6.6(7.2)$ & $5.2(5.7)$ & $5.8(6.4)$ \\
$\quad$ Backward & $4.7(5.4)$ & $5.1(5.1)$ & $4.1(4.8)$ & $3.4(2.8)$ \\
Numbers & & & & \\
$\quad$ Forward & $5.4(5.9)$ & $6.6(7.2)$ & $5.4(5.9)$ & $6.2(6.1)$ \\
$\quad$ Backward & $5.4(5.2)$ & $7.0(7.8)$ & $4.8(5.0)$ & $6.9(7.6)$ \\
\hline
\end{tabular}

he could think of and then respond on the basis of the forward association. The purpose of this experiment was to replicate completely the Nelson et al (cf. Experiment II) study under rapidly paced conditions. Thus, the same materials and acquisition procedures were used, except that recall was paced at the same rate as in acquisition.

\section{VERBAL MATERIAL}

Trigrams for eight-item PA lists were: for high meaningfulness/high similarity, LAD, LAG, LED, LEG, BAD, BAG, BED, BEG; for high meaningfulness/low similarity, ALP, BOX, CUB, END, GEM, J A R, SHY, WIT; for $10 \mathrm{w}$ meaningfulness/high similarity, FAJ, FAQ, FIJ, FIQ, ZAJ, ZAQ, ZIJ, ZIQ; and for low meaningfulness/low similarity, BIW, CUQ, DEJ, GOX, KYV, QAZ, VUB, ZOF. Respective mean Archer (1960) association values were $99.25,99.40,18.25$, and 11.87. For variations in stimulus characteristics, response terms were the digits 1-8. The pairs were reversed to form lists varying in response characteristics. PROCEDURE

Each $S$ learned a single list by the anticipation method to a $6 / 8$ correct criterion. Slides of the verbal materials were projected via a Kodak Carousel projector, driven by an auxiliary timer at a $2: 2$-sec rate. There was no intertrial interval. On test presentation, trigrams were spelled and digits pronounced. Guessing was not required. Sequences of pairs were presented in five unsystematically varied orders, with the restriction that at least two pairs intervene between a pair and its re-presentation in the next sequence. The order of sequences was changed for each $S$ in each condition.

Immediately following acquisition, instructions were given for forward recall for half of the Ss and for backward recall for the remaining Ss. Instructions were equated for word length. Under conditions of recall, either the stimuli or responses were projected on the screen in a random order for $2 \mathrm{sec}$ each. This presentation was followed by a 2 -sec blank prior to the next item. No feedback was ever provided, and $S$ was encouraged to guess. The test cues were then reordered and a second test, paced at an $8-\mathrm{sec}$ rate, was given. The test items remained on the screen for the full $8 \mathrm{sec}$.

The forward and backward recall of each of the eight lists resulted in 16 conditions ( 2 by 2 by 2 by 2 ) with 10 Ss in each. The Ss, who received points toward their introductory psychology grade, were assigned to conditions in blocks of 16 , with one $\mathrm{S}$ from each condition per block. Order of conditions within blocks was determined by a table of random numbers. RESULTS AND DISCUSSION

Statistical analysis of the number of errors (omission plus emission) in acquisition indicated that meaningfulness, similarity, and Meaningfulness by Similarity were significant sources of variation. Stimulus vs response location and the interaction of this variable with meaningfulness approached, but did not attain, the criterion of significance. Recall direction and all interactions including this variable were not significant, suggesting that groups were equated across this variable. Respective mean errors for conditions of high meaningfulness were 85.02 and 31.57 for conditions of high and low similarity; for low meaningfulness these respective means were 180.17 and 71.20. For high meaningfulness mean errors were 57.52 and 59.07 , respectively, for stimulus and response locations; for low meaningfulness these respective means were 115.25 and 136.12. Fisher's least significant difference (LSD) was 18.89 . Similarity impaired acquisition to a greater extent when meaningfulness was low than when high, and low relative to high meaningfulness increased difficulty to a greater extent when located on the response side. These findings were consistent with those reported by Nelson et al (1970). A statistical comparison of the two studies indicated that, although fewer overall errors were made in this experiment, none of the interactions with the experiment source were reliable.

Table 1 presents the mean number of correct recalls for the 2 - and 8-sec tests. Statistical analysis of recall at the $2-\mathrm{sec}$ rate indicated that all main effects were significant, as were the interactions of Similarity by Type of Material, Recall Direction by Type of Material, and Similarity by Recall Direction by Type of
Material. The LSD was 1.25 . When trigrams were being recalled, the relative differences between forward and backward recall increased as stimulus meaningfulness and similarity decreased. The greatest discrepancy occurred when both meaningfulness and similarity were low. When single-digit numbers were being recalled, there were no reliable differences between forward and backward recall.

Although meaningfulness did not reliably interact with recall direction, this pattern of findings was essentially consistent with that found by Nelson et al (1970; cf. Table 2). However, a comparison of the recall scores for the two experiments suggested that the faster rate of test reduced the level of recall. Thus, the recall data for the two experiments were included in a single analysis with rate of test ( 2 vs $8 \mathrm{sec}$ ) as the fifth factor. All main effects were significant, as were the interactions of Meaningfulness by Recall Direction, Similarity by Type of Material, Recall Direction by Type of Material, Meaningfulness by Similarity by Type of Material, and Similarity by Recall Direction by Type of Material. Although significantly more items were recalled under the 8- relative to the $2-\sec$ test conditions, not a single factor interacted with rate of test. This lack of interaction suggested that the relationships between meaningfulness-similarity and recall direction were independent of the length of the time allowed for recall, at least up to $8 \mathrm{sec}$.

A separate analysis of the second recall test in this study, which was paced at $8 \mathrm{sec}$, indicated a pattern of statistically reliable sources identical to that obtained for the initial 2-sec recall test. A statistical comparison of the 8-sec recall scores of this experiment with those reported by Nelson et al indicated that meaningfulness, similarity, type of material, recall direction, and the third-order interaction among these factors were significant. Experiment and all interactions with this source were not statistically reliable. The results of this analysis, however, must be interpreted with caution, since the increment in recall for the 8 -sec test in this study could have been a result of a longer retrieval period or of the fact that this was the second retrieval.

\section{REFERENCES}

ARCHER, E. J. A re-evaluation of the meaningfulness of all possible CVC trigrams. Psychological Monographs, 1960, 74 (10) Whole No. 497.

EKSTRAND, B. R. Backward associations. Psychological Bulletin, 1966, 65, 50-64.

NELSON, D. L., ROWE, F. A., ENGEL, J. E., WHEELER, J., \& GARLAND, R. M. Backward relative to forward recall as a function of stimulus meaningfulness and formal interstimulus similarity. Journal of Experimental Psychology, 1970, 83, 323-328. 